\title{
PHOTOCHEMISTRY OF PHYCOBILIPROTEINS: RECIPROCITY OF REVERSIBLE PHOTOCHEMISTRY AND AGGREGATION IN PHYCOERYTHROCYANIN FROM Mastigocladus laminosus
}

\author{
S. Siebzehnrübl, R. Fischer, W. Kufer and H. Scheer* \\ Botanisches Institut der Universität, Menzinger Str. 67, D-8000 München 19, W. Germany
}

(Received 23 September 1988; accepted 6 January 1989)

\begin{abstract}
Native PEC from the cyanobacterium, Mastigocladus laminosus, and its isolated $\alpha$ subunit show photoreversibly photochromic reactions with difference-maxima around 502 and $570 \mathrm{~nm}$ in the spectral region of the $\alpha-84$ phycoviolobilin chromophore. (b) Native PEC and its $\beta$-subunit show little if any reversible photochemistry in the $600-620 \mathrm{~nm}$ region, where the phycocyanobilin chromophores on the $\beta$-subunit absorb maximally. (c) Reversible photochemistry is retained in ureadenatured $\mathrm{PEC}$ at $\mathrm{pH}=7.0$ or $\mathrm{pH} \leqslant 3$. The difference maxima are shifted to 510 and $600 \mathrm{~nm}$, and the amplitudes are decreased. An irreversible absorbance increase occurs around $670 \mathrm{~nm}(\mathrm{pH} \leqslant 3)$. (d) The amplitude of the reversible photoreaction difference spectrum is maximum in the presence of 4-5 $M$ urea or $1 M \mathrm{KSCN}$, conditions known to dissociate phycobiliprotein aggregates into monomers. At the same time, the phycocyanobilin chromophore(s) are bleached irreversibly. (e) The amplitude becomes very small in high aggregates, e.g. in phycobilisomes. (f) In a reciprocal manner, the phototransformation of native PEC leads to a reversible shift of its aggregation equilibrium between trimer and monomer. The latter is favored by orange, the former by green light. (g) It is concluded that the phycoviolobilin chromophore of PEC is responsible for reversible photochemistry in PEC, and that there is not only an influence of aggregation state on photochemistry, but also vice versa an effect of the status of the chromophore on aggregation state. This could constitute a primary signal in the putative function as sensory pigment, either directly, or indirectly via the release of other polypeptides, via photodynamic effects, or the like.
\end{abstract}

\section{INTRODUCTION}

Plant and algal biliproteins have two major functions: The phycobiliproteins are light-harvesting pigments for photosynthesis in cyanobacteria, rhodophytes and cryptophytes (Bryant, 1988; Gantt, 1986; Glazer, 1985; MacColl and Guard-Friar, 1987; Scheer, 1982, 1986; Wehrmeyer, 1983; Zuber, 1986). The phytochrome(s) are photoreversibly photochromic light-sensory pigments in green plants and some algae (Furuya, 1983; Pratt, 1982; Rüdiger and Scheer, 1983; Song, 1983). The protein moieties of the two classes are at most distantly related, but the chromophores are surprisingly similar not only in their molecular structure, but also in their interactions with the respective apoproteins (Rüdiger and Scheer, 1983).

Many cyanobacteria also show responses which are controlled by light in a fashion suggesting photoreversibly photochromic pigments as photoreceptors (see L. O. Björn, 1979; Bogorad, 1975; Scheer, 1982; Tandeau de Marsac, 1983). Action spectra have been obtained for a variety of responses including chromatic adaptation and photomorphogenesis. The putative photoreceptors have been termed

\footnotetext{
* To whom correspondence should be addressed.
}

accordingly as adaptochromes and phycomorphochromes (Bogorad, 1975). The subsequent search for photoreversibly photochromic pigments (reviews in L. O. Björn, 1979; Björn and Björn, 1980) resulted in the spectral characterization of at least four different fractions termed phycochromes $a, b$, $c$ and $d$, in analogy to the plant photoreceptor, phytochrome. In no case has their been conclusive evidence, however, that the phycochromes are indeed the putative photoreceptors.

The situation became even more complex by reports of several groups that phycobiliproteins can be induced to photochemistry reminiscent of these phycochromes by mild denaturation in vitro (deKok et al., 1981; John et al., 1985; Murakami and Fujita, 1983; Ohad et al,,1980; Ohki and Fujita, 1979a; Schmidt et al., 1988) or photobleaching in vivo (Ohki and Fujita, 1979b). In at least one case, it has furthermore been shown that such mild denaturation treatments can change the aggregation equilibrium from tri- to monomeric (Murakami and Fujita, 1983), e.g. that a decrease in aggregation increases the susceptibility of the chromophore(s) to photochemistry. This has been taken as an indication that phycobiliproteins may have secondary functions besides light-harvesting. A difficulty in any such proposal suggesting a dual function in phycobiliproteins, is the small polypeptide size. 
Phycoerythrocyanin (PEC) $†$ is a phycobiliprotein from several species of cyanobacteria (Bryant, 1982), which is photoreactive already in its native state (Kufer, 1988). The $\alpha$-subunit, which carries an unusual phycoviolobilin" chromophore (Fig. 1) (Bishop et al., 1987) shows even more intense spectral changes, and this subunit seems to be identical (Björn and Björn, 1980) to phycochrome $b$ isolated by G. S. Björn (1979). Although no action spectrum for photomorphogenesis corresponds to the action spectrum for photoconversion of isolated PEC or its $\alpha$-subunit, it has been discussed as a component in the action spectrum of akinete germination in Anabaena variabilis (Björn and Björn, 1980; Braune et al., 1988).

In continuing a systematic study on the photoreactivity of phycobiliproteins (Schmidt et al., 1988), we have now further characterized the photochemistry of PEC. Here, we wish to report on its photoreactivity observed under different conditions from highly aggregated to fully denatured PEC, the reactivity of the subunits under similar conditions, and the mutual interdependence of phototransformation and aggregation. The modulation of aggregate size could principally constitute a signal in the cell.
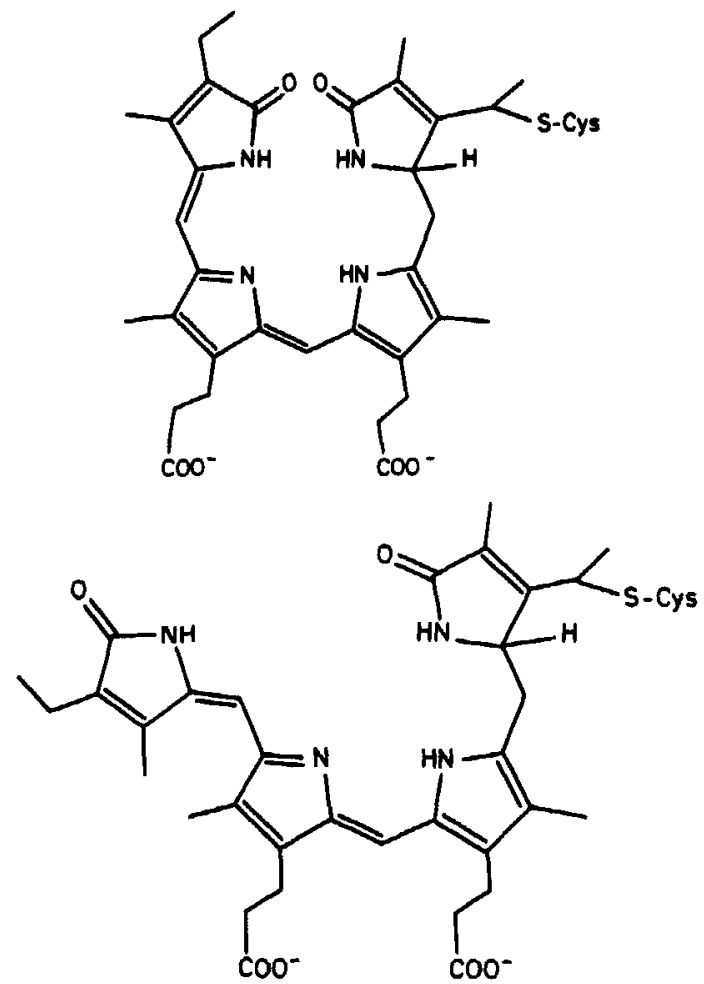

Figure 1. Structures of phycoviolobilin chromophores in $\mathrm{Z}, \mathrm{Z}$ and $\mathrm{Z}, \mathrm{E}$-configuration.

+ Abbreviations: PC, phycocyanin; PE, phycoerythrin; APC, allophycocyanin; PEC, phycoerythrocyanin; $P_{r}$ and $P_{f r}$, phytochrome in the red and far-red absorbing form, respectively.

* The term phycoviolobilin has been used instead of phycobiliviolin (Bishop et al., 1987), in order to be coherent with nomenclature of other phycobiliprotein chromophores.

\section{MATERIALS AND METHODS}

Mastigocladus laminosus was cultivated in Castenholz (1970) medium in $300 \ell$ batches at the Gesellschaft für biotechnologische Forschung, Stöckheim (W. Germany) and stored deep frozen.

For preparation of phycoerythrocyanin (PEC) we used a method, which was very similar to the one given by Füglistaller et al. (1981). After separation of the biliproteins by chromatography on DEAE cellulose, PEC was concentrated by ammonium sulfate precipitation. The subunits of PEC were prepared by isoelectric focusing as used before for PC from the same organism (Köst-Reyes et al., 1987). After elution from the gel, the subunits were renatured by dialysis against potassium phosphate buffer $(100 \mathrm{mM} / \mathrm{pH} 7.0)$ at first at room temperature and subsequently at $4 \mathrm{C}$.

Phycobilisomes were provided to us by Professor W. Sidler (ETH, Zürich) as polyethylenglycol precipitate They were dialyzed against $0.9 \mathrm{M}$ potassium phosphate buffer ( $\mathrm{pH} 7.0$ ) and repurified by a sucrose density gradient ultracentrifugation $(8.6$ to $27.4 \%$ wt/wt, $16 \mathrm{~h}$, $180000 \mathrm{~g}$ ). Two heavy fractions were investigated which were isolated at 14.1 and $20.9 \%$ sucrose, and which differed in their PEC content (vide infra).

Absorption spectra were recorded on a model 8451 A spectrophotometer (Hewlett-Packard). The absorption difference spectra were measured with a ZWSII spectrophotometer (Sigma Chemical Co., Berlin, W. Germany) in split beam mode with thermostated cell holders. One of the cuvettes could be irradiated in the photometer by a Lumilux $150 \mathrm{~W}$ light source (Volpi, Denzlingen, W. Germany) equipped with a light guide and suitable interference filters (orange $=600 \mathrm{~nm}$, fwhh $=9.1 \mathrm{~nm}$; green $=$ $500 \mathrm{~nm}$, fwhh $=7.3 \mathrm{~nm}$; Seitner Mess- und Regeltechnik Herrsching, W. Germany). During irradiation and al measurements the samples were thermostated at $15^{\circ} \mathrm{C}$

Photochemistry was generally induced by illuminating the samples for $3 \mathrm{~min}$ with $600 \mathrm{~nm}$ light, or for $6 \mathrm{~min}$ with $500 \mathrm{~nm}$ light. The saturation was checked routinely by further irradiation with the same light, and the irradiation time increased if necessary.

The aggregation state of PEC was studied by sucrosedensity gradient centrifugation (Martin and Ames, 1961) in a model Ultrospin 55 ultracentrifuge (LKB, München) at $238000 \mathrm{~g}$. In the reactions relating irradiation with aggregation, a PEC stock-solution $\left(A_{570}=0.6 \mathrm{~cm}^{-1}\right)$ was irradiated alternately with green and orange light. Before the first and after every illumination an aliquot $(0.2 \mathrm{~m} \ell)$ was applied to a sucrose gradient $(5 \mathrm{~m} \ell, 7$ to $17 \% \mathrm{wt} / \mathrm{wt})$. The trimeric phycocyanin from Mastigocladus laminosus $(106.1 \mathrm{kDa})$ and horse-heart myoglobin $(17.5 \mathrm{kDa})$ were used as reference. The colored bands were withdrawn and quantified by absorption spectroscopy.

\section{RESULTS}

\section{Photochemistry of native pigments}

When PEC was irradiated either with orange $(600 \mathrm{~nm})$ or green light $(500 \mathrm{~nm})$, photochemistry was observed with absorption difference extrema at 502 and $570 \mathrm{~nm}$. The extremum at $502 \mathrm{~nm}$ is positive upon irradiation with orange, negative with green light, and the responses were inverted for the $570 \mathrm{~nm}$ difference band. When the first irradiation was followed by a second one with 'opposite' light, the difference extrema were inverted, but their amplitudes increased. The amplitudes then remained constant at subsequent alternate reactions 
induced by the two light qualities. This indicates that PEC is isolated in an intermediate state under normal conditions (subdued daylight) of harvest and isolation. All further experiments were, therefore, performed after saturating pre-irradiation with either orange or green light.

The absorption spectra and absorption difference spectra for photochemistry after such a preirradiation are shown in Fig. 2. The shape of the difference spectra is the same as without preirradiation, but the amplitude is now maximum. This amplitude will be expressed throughout as relative absorption difference $\Delta \Delta \mathrm{A}$

$$
\Delta \Delta \mathrm{A}=\left|\frac{\Delta \mathrm{A}_{\text {orange }}-\Delta \mathrm{A}_{\text {green }}}{\mathrm{A}_{\max }^{\text {green }}}\right| 100[\%]
$$

$\Delta \mathbf{A}_{\text {orange }}$ and $\Delta \mathrm{A}_{\text {green }}$ denote the maximum absorption changes in the orange and green spectral regions, respectively, and $A_{\max }^{\text {green }}$ the maximum absorption in the orange band after saturating green irradiation. $\Delta \Delta \mathrm{A}$ values for different treatments and samples are listed in Table 1.

The orange/green light reaction with difference maxima at 502 and $570 \mathrm{~nm}$ is fully reversible for 3-4 subsequent cycles of orange-green irradiation throughout most of the visible spectral region. During prolonged irradiations, however, there is often a concomitant irreversible response in the $603 \mathrm{~nm}$ region where the phycocyanobilin chromophores of the $\beta$-subunit absorb (see below). This wavelength suggests that some irreversible photochemistry occurs on the phycocyanobilin chromophore(s) $\left(\lambda_{\max }>580 \mathrm{~nm}\right)$ situated at cys-84 or cys-155 on the $\beta$-subunit, whereas the reversible photochemistry is related to the phycoviolobilin chromophore $\left(\lambda_{\max }=\right.$ $570 \mathrm{~nm}$ ) located at position cys- 84 on the $\alpha$-subunit. The assignment of reversible photochemistry to chromophore $\alpha-84$, is supported by experiments with isolated subunits of PEC. The $\alpha$-subunit shows the same reversible difference spectrum, but its amplitude is now increased to $50 \%$ (Fig, 3). The $\beta$-subunit shows only an irreversible bleaching at $603 \mathrm{~nm}$ (W. Kufer and G. S. Björn, 1989).

\section{Partly and fully denatured pigments}

Upon addition of increasing amounts of urea, the difference extrema of the reversible reaction remain stationary up to denaturant concentrations of $4 M$ (Table 1). At the same time, the amplitudes increase. At higher urea concentrations and the $\mathrm{pH}$ kept at 7.0, the amplitudes decrease again, and the extrema shift gradually to 510 and $600 \mathrm{~nm}$. Reversible photochemistry is retained up to $8 M$ urea, under which conditions the polypeptide chains are fully unfolded (Fig. 4A, B).

Reversible photochemistry is also retained in denatured $\mathrm{PEC}$ at low $\mathrm{pH}$. Table 2 shows the photochemical activity after pre-irradiations with two dif-
(A)

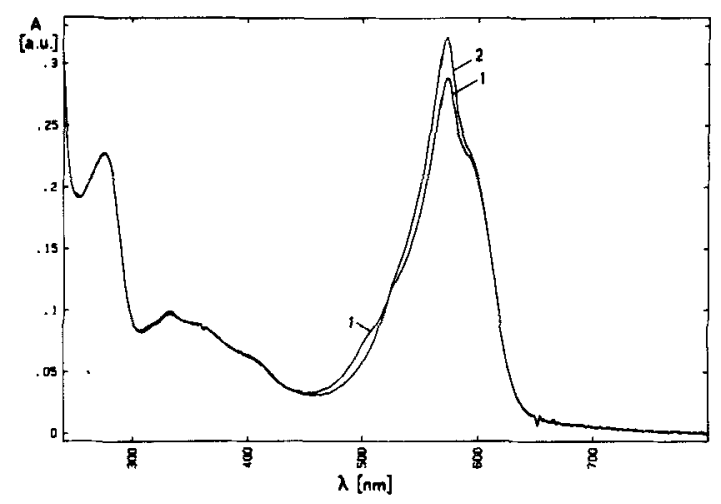

(B)

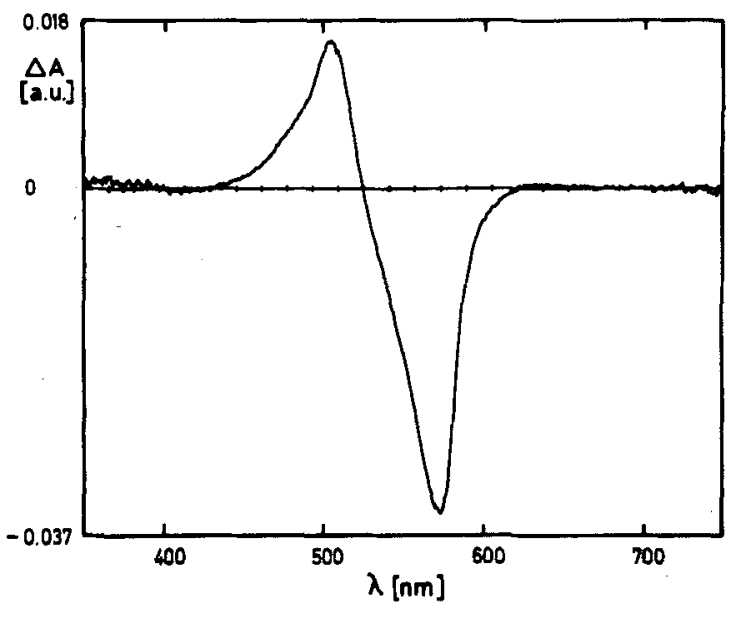

(C)

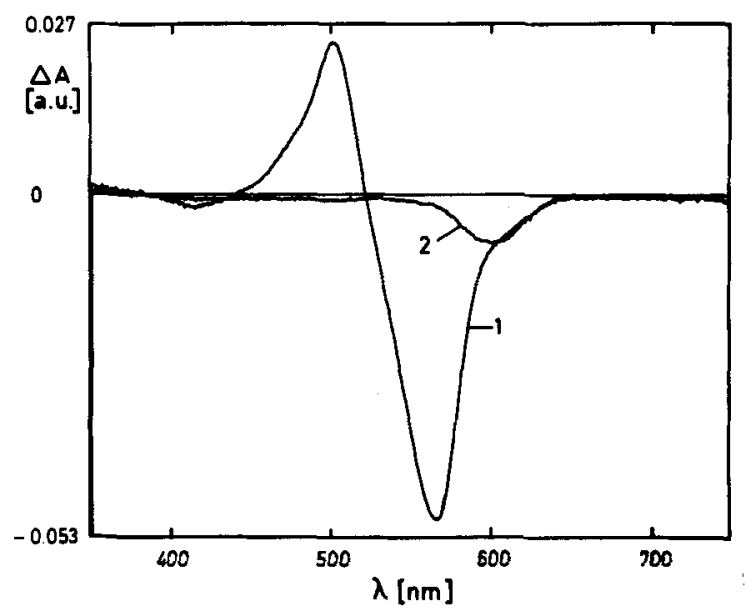

Figure 2. Absorption spectra (A) of native PEC (100 $\mathrm{m} M$ phosphate buffer, $\mathrm{pH}=7$ ) after saturating pre-irradiation (see text) with $600 \mathrm{~nm}$ light (trace 1) and subsequent saturating irradiation at $500 \mathrm{~nm}$ (trace 2). Absorption difference spectra (B) of trace 1 minus trace 2. (C) Absorption difference spectrum ( 3 min orange minus 6 min green pre-irradiation) of a solution of PEC in $100 \mathrm{~m} M$ phosphate buffer containing $3 M$ urea (trace 1 ). Difference spectrum ( 3 min orange followed by 6 min green minus 6 min green pre-irradiation) of the same sample (trace 2 ). 
Table 1. Absorption difference extrema and amplitudes of different PEC samples or samples subjected to different pre-treatments

\begin{tabular}{|c|c|c|c|c|c|c|}
\hline \multirow[b]{2}{*}{ Sample } & \multirow{2}{*}{$\begin{array}{c}\mathrm{C}_{\text {buffer }}{ }^{*} \\
(\mathrm{~m} M)\end{array}$} & \multirow{2}{*}{$\begin{array}{l}C_{\text {urea }} \\
(M)\end{array}$} & \multicolumn{4}{|c|}{ pH Difference extrema (nm) $\Delta \Delta \mathbf{A}^{\dagger}$} \\
\hline & & & & Orange & Green & $(\%)$ \\
\hline PEC & 5 & 0 & 7.0 & 568 & 503 & 20 \\
\hline PEC & 100 & 0 & 7.0 & 570 & 503 & 18 \\
\hline PEC & 5 & 1 & 7.1 & 569 & 503 & 31 \\
\hline PEC & 100 & 1 & 7.1 & 569 & 503 & 32 \\
\hline PEC & 5 & 4 & 7.3 & 566 & 502 & 36 \\
\hline PEC & 100 & 4 & 7.3 & 567 & 502 & 35 \\
\hline PEC & 5 & 6 & 7.5 & 568 & 504 & 20 \\
\hline PEC & 100 & 6 & 7.5 & 600 & 510 & 12 \\
\hline PEC & 100 & 8 & 7.0 & 599 & 515 & 6 \\
\hline PEC & 100 & 8 & 3.0 & 598 & 507 & 13 \\
\hline PEC-monomer & 100 & $\ddagger$ & 7.0 & 565 & 504 & 36 \\
\hline$\alpha$-Subunit & 100 & 0 & 7.0 & 569 & 504 & 50 \\
\hline
\end{tabular}

*Buffer = potassium phosphate buffer.

tSee text for definition of $\Delta \Delta \mathrm{A}$.

$\ddagger 1 M \mathrm{KSCN}$, no urea.

ferent light qualities (orange or green), which were given in the native state. The subsequent denaturation with acidic urea was then followed by an inductive illumination (green or orange, respectively).

(A)

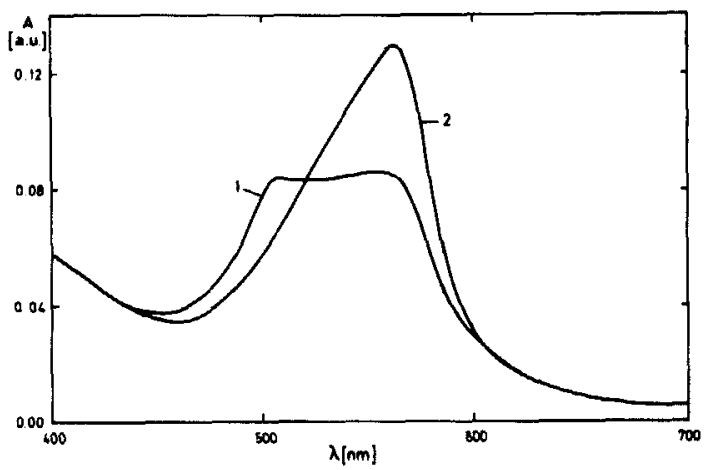

(B)

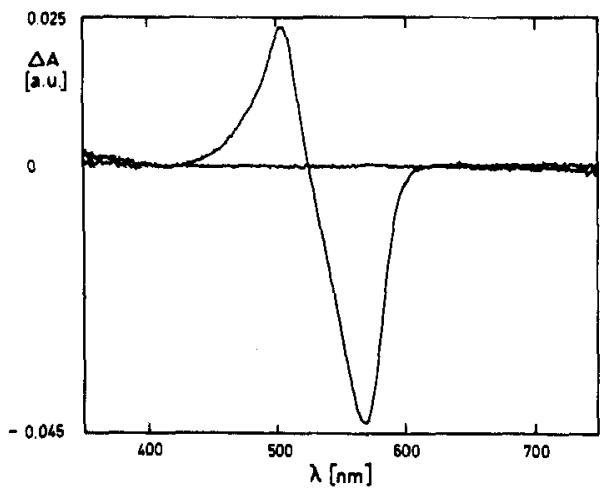

Figure 3. Absorption spectra (A) of $\alpha$-subunit of PEC after saturating pre-irradiation with $600 \mathrm{~nm}$ light (trace 1) and subsequent saturating irradiation at $500 \mathrm{~nm}$ (trace 2). Absorption difference spectra (B) of trace 1 minus trace 2.
Difference spectra obtained by a similar protocol, but with the second irradiation carried out with white instead of monochromatic light, are shown in Fig. 5. They show a second absorption increase at $667 \mathrm{~nm}(2.1 \%$ of the maximum absorption). This absorption change is positive irrespective of the preirradiation, and is not reversible by any further irradiations. It is probably correlated with the phycocyanobilin chromophores partly being present in the E-configuration, as described previously for phycocyanin (Schmidt et al., 1988). These chromophores transform irreversibly to the Z-isomers in the denatured protein.

Another irreversible reaction of the phycocyanobilin chromophores is best observed at intermediate urea concentrations (Fig. 2C). The change in the phycoviolobilin spectral region is fully reversible, whereas a bleaching at $603 \mathrm{~nm}$ persists. The easy photooxidation of 2,3-dihydrobiliverdins, to which class the phycocyanobilin chromophore belongs, is well known (Scheer, 1982). The chromophore is protected, however, in native phycocyanin by noncovalent interactions with the apoprotein, and gains its normal reactivity only after partial uncoupling of these interactions, e.g. by unfolding of the polypeptide. Photobleaching of native phycocyanin is much slower and the products are hitherto unknown, and the reaction mechanism is poorly understood. It seems to involve at least partly a reaction via the triplet state, as inferred from the effect of oxygen on the kinetics (Scheer, 1987) and photodynamic effects (Morcos et al., 1988).

\section{Interrelations of photochemistry and aggregation}

Native PEC isolated from $M$. laminosus, separates upon ultracentrifugation into two bands with mobilities corresponding to trimers (= heterohex- 
(A)

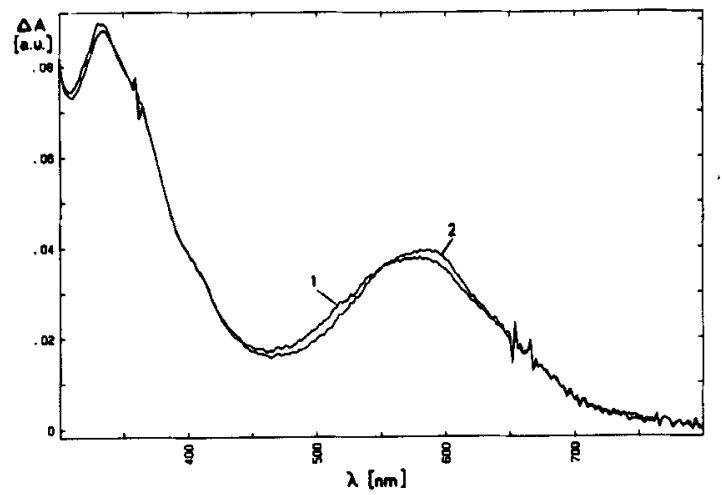

(B)

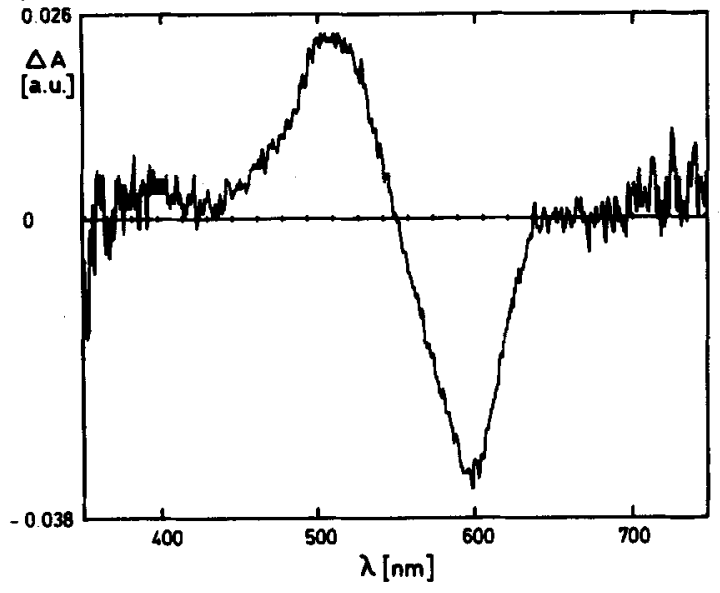

Figure 4. (A) Absorption spectra of PEC in $100 \mathrm{~m} M$ phosphate buffer containing $8 M$ urea, at neutral $\mathrm{pH}$. Preirradiated with orange light $(6 \mathrm{~min})$ in the native state, and then denatured by addition of solid urea (trace 1), and after $6 \mathrm{~min}$ green light (trace 2). (B) Difference spectrum of trace 1 minus trace 2 .

amers, $\left.(\alpha \beta)_{3}\right)$ and monomers (= heterodimers, $\left.\alpha \beta\right)$. Intermediate concentrations of urea are expected to cause progressive dissociation of biliprotein trimers to monomers. In PEC, this is paralleled by the aforementioned increase in difference amplitude. A similar increase is found after addition of the chaotropic reagent, KSCN (Table 1), which is known to dissociate trimers of PC and APC into
(A)

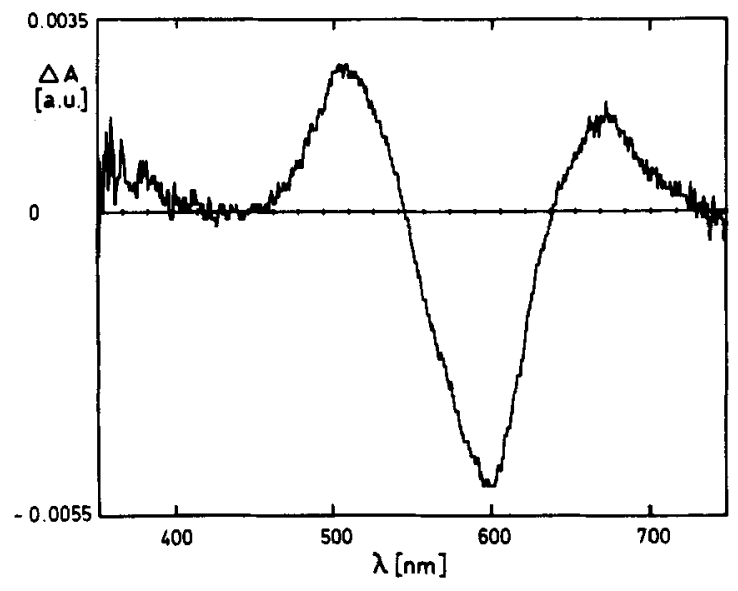

(B)

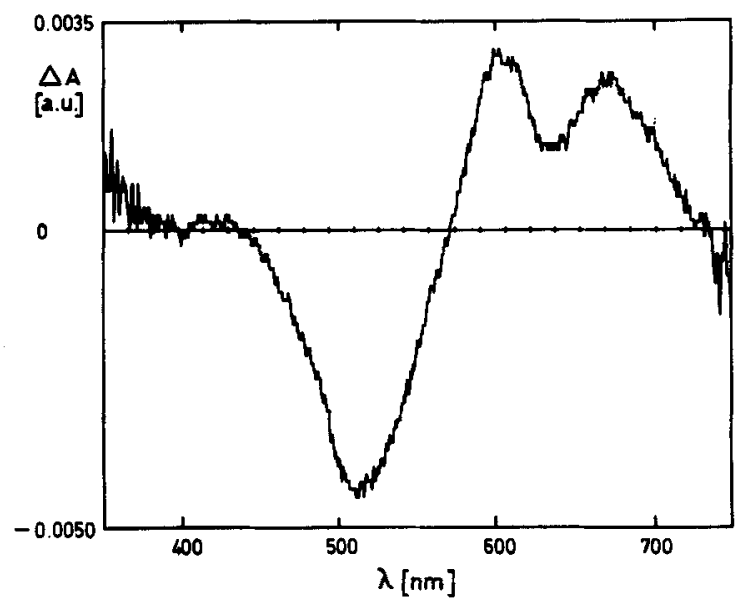

Figure 5. Absorption difference spectra of PEC in acid urea. Native PEC irradiated with green (A) or orange light (B), then denatured by addition of urea $(8 M)$ and brought to $\mathrm{pH}=2$ with hydrochloric acid. Difference spectra (after minus before) between these solutions and the same solutions irradiated with white light.

monomers (MacColl and Guard-Friar, 1987). The $\Delta \Delta \mathrm{A}$-values of samples treated with $4 M$ urea or $1 M \mathrm{KSCN}$ are similar. The difference amplitudes are not only increased on a relative, but even on an absolute scale (decrease of $A_{\max }$ by $20 \%$, increase of

Table 2. Reversible photochemistry of PEC in the denatured state after different pre-irradiations (the latter were carried out in the native state before addition of the denaturant, urea, and titration to $\mathrm{pH}=3$ with phosphoric acid)

\begin{tabular}{|c|c|c|c|c|}
\hline \multirow[b]{3}{*}{$\begin{array}{l}\text { Pre- } \\
\text { irradiation }\end{array}$} & \multirow{3}{*}{$\begin{array}{l}\text { Inductive } \\
\text { irradiation }\end{array}$} & \multicolumn{3}{|c|}{ Absorption difference spectra } \\
\hline & & \multicolumn{2}{|c|}{ Extrema (nm) } & \multirow{2}{*}{$\frac{\Delta \Delta \mathrm{A}^{*}}{(\%)}$} \\
\hline & & $\Delta A_{\max }^{\text {green }}$ & $\Delta A_{\max }^{\text {orange }}$ & \\
\hline $\begin{array}{l}\text { Green } \\
\text { Orange }\end{array}$ & $\begin{array}{l}\text { Orange } \\
\text { Green }\end{array}$ & $\begin{array}{l}598 \\
602\end{array}$ & $\begin{array}{l}507 \\
510\end{array}$ & $\begin{array}{l}13.0 \\
12.7\end{array}$ \\
\hline
\end{tabular}

"See text for definition of $\Delta \Delta A$. 
$\Delta \Delta \mathrm{A}$ by $80 \%$ ). It should be noted, however, that the spectra of PEC are distinctly different with the two reagents, e.g. $4 M$ urea produces a red shoulder, whereas addition of $1 M \mathrm{KSCN}$ causes the appearance of a distinct second maximum (spectra not shown). This indicates that additional differences besides disaggregation are induced by the two reagents.

We have been unable hitherto to isolate pure trimers of PEC, a correlation of reversible photoreactivity with monomers only is therefore not possible. In isolated phycobilisomes and large, energetically coupled PC-PEC aggregates, however, we have been able to detect only very little reversible photochemistry. However, the amplitude increased up to nine-fold after dissociation of these complexes by dialysis against buffer of low ionic strength (Table 3). The magnitudes of the increases were dependent on the preparations. A phycobilisome sample prepared in polyethylene glycol (provided by $W$. Sidler) showed a smaller effect than a sample which was freshly re-fractionated from the former by sucrose-density gradient ultracentrifugation. A small but still distinct increase was also found upon dissociation of the second-heaviest band isolated from the gradient (PC-PEC aggregate, see footnotes Table 3). This indicates that the photochemistry of PEC is decreased by increasing aggregation, and monomers show maximum photochemistry.

Table 3. Photochemistry of large biliprotein aggregates in $0.9 \mathrm{M}$ phosphate buffer, $\mathrm{pH}=7$, and after dissociation by dialysis against $0.1 \mathrm{M}$ buffer

\begin{tabular}{|c|c|c|c|}
\hline \multirow{3}{*}{$\begin{array}{l}\text { Preparation } \\
\text { Aggregation } \\
\text { state }\end{array}$} & \multicolumn{3}{|c|}{ Absorption difference spectra } \\
\hline & \multicolumn{2}{|c|}{ Extrema (nm) } & \multirow{2}{*}{$\frac{\Delta \Delta \mathrm{A}^{*}}{(\%)}$} \\
\hline & $A_{\max }^{\text {ereen }}$ & $A_{\max }^{\text {orange }}$ & \\
\hline Phycobilisomes $\dagger$ & & & \\
\hline $\begin{array}{l}\text { aggregated } \\
\text { dissociated }\end{array}$ & $\begin{array}{l}502 \\
502\end{array}$ & $\begin{array}{l}567 \\
567\end{array}$ & $\begin{array}{l}0.36 \\
1.08\end{array}$ \\
\hline $\begin{array}{l}\text { Phycobilisomes } \ddagger \\
\text { native } \\
\text { dissociated }\end{array}$ & $\begin{array}{l}502 \\
504\end{array}$ & $\begin{array}{l}567 \\
567\end{array}$ & $\begin{array}{l}0.31 \\
2.82\end{array}$ \\
\hline $\begin{array}{l}\text { PC-PEC aggreg. } \\
\text { native } \\
\text { dissociated }\end{array}$ & $\begin{array}{l}509 \\
506\end{array}$ & $\begin{array}{l}572 \\
571\end{array}$ & $\begin{array}{l}2.60 \\
3.21\end{array}$ \\
\hline
\end{tabular}

"See text for definition of $\Delta \Delta \mathrm{A}$.

†Phycobilisomes provided by $W$. Sidler.

\$Phycobilisomes repurified by sucrose density gradient. Heaviest band isolated at $20.9 \%$ sucrose. $\lambda_{\max }^{\mathrm{abs}}=620$, 576(shoulder), 652(shoulder) $\mathrm{nm}, \quad \lambda_{\max }^{\text {nuor }}=665$, 683(shoulder) $\mathrm{nm}$ with $560 \mathrm{~nm}$ excitation. Absorption maxima as in Nies and Wehrmeyer (1980), the shorter emission maximum indicates (partial) loss of terminal emitters.

8Band isolated at $14.1 \%$ sucrose after centrifugation. $\lambda_{\max }^{\mathrm{aba}}=$ 618,576 (shoulder) $\mathrm{nm}, \lambda_{\max }^{\text {nuor }}=652 \mathrm{~nm}$ with $560 \mathrm{~nm}$ excitation.
In a separate set of experiments, we have studied the inverse effect, e.g. the influence of preirradiation with different light qualities on the aggregation of PEC. The results of the experiments are summarized in Table 4. A sample of PEC was irradiated alternately with orange and green light. Aliquots of the original sample and of the sample after the subsequent light treatments were then loaded on a sucrose gradient and analyzed for aggregate distribution by ultracentrifugation. In every case, the sample is a mixture of mono- and trimeric PEC, but the amount of higher aggregates is always increased after irradiation with green light, and decreased after irradiation with orange light. Although some damping of the oscillations is observed (possibly due to irreversible photochemistry of the phycocyanobilin chromophores, vide supra), this response clearly demonstrates a mutual relationship between chromophore photochemistry and aggregation.

\section{DISCUSSION}

Phycochrome $b$ has been characterized first by Björn and Björn (1976) as a photoreversibly photochromic component in extracts from Tolypothrix distorta. It has subsequently been found in several other cyanobacteria which were all distinct by containing PEC instead of PE (Björn, 1980). From whole algae, the photoactivity could be traced to a pigment 'which seems to be identical to the $\alpha$-subunit of PEC' (Björn and Björn, 1980). Whereas the enrichment of phycochrome $b$ has usually been followed by a photoactivity assay, the present study used a different approach: Phycoerythrocyanin was isolated as integral pigment, and subsequently separated into its subunits by isoelectric focusing in the presence of urea. The photoreversibly-photochromic responses obtained with integral PEC and its $\alpha$-subunit, are identical to the ones reported for phycochrome $b$, and such changes are absent in the

Table 4. Changes in aggregation state of PEC after isolation (= daylight) and subsequent alternatingly irradiation with orange and green light

\begin{tabular}{lc}
\hline Irradiation & $Q^{\text {up/ low }}$ \\
\hline Daylight & 0.82 \\
$10 \min 500 \mathrm{~nm}$ & 0.47 \\
$5 \mathrm{~min} 600 \mathrm{~nm}$ & 0.76 \\
$10 \mathrm{~min} 500 \mathrm{~nm}$ & 0.32 \\
$5 \mathrm{~min} 600 \mathrm{~nm}$ & 0.66 \\
$10 \mathrm{~min} 500 \mathrm{~nm}$ & 0.35 \\
\hline
\end{tabular}

$Q^{\text {up/ } / \text { low }}$ is the ratio of absorption of the upper (= monomer) to lower ( $=$ trimer) band. 
$\beta$-subunit. Quantitatively, the light-induced absorbance changes are very dependent on the state of the PEC. However, even without a proper quantification it appears that most if not all photoactivity in extracts of $\boldsymbol{M}$. laminosus can be accounted for by the $\alpha$-PEC present. This constitutes further support that the $\alpha$-subunit of PEC is indeed identical with phycochrome $b$.

This subunit contains a rare bilin chromophore, e.g. phycoviolobilin (Fig. 1), which has a conjugation system intermediate in length between those of phycocyanobilin and phycoerythrobilin (Bishop et al., 1987). It lacks a double-bond between rings $A$ and $B$, but the one between rings $C$ and $D$ is still present. The latter $(\Delta 15)$ is the one involved in the photochemistry of phytochrome: it is Z-configured in $P_{r}$ and $E$-configured in $P_{\mathrm{fr}}$ (Rüdiger et al., 1983). The reversible photochemistry observed in partly denatured and/or dissociated phycocyanin has also been related to isomerization of this double-bond from optical spectra (Schmidt et al., 1988), but a definite proof is still lacking.

In the violin chromophore, isomerization is principally possible at the $\Delta 10$ - or $\Delta 15$-double bond. We suggest that isomerization takes place in the $\alpha$ subunit of PEC at the $\triangle 15$-double bond as well for the following reasons: (1) The difference spectrum is similar to that of the PCB chromophore in PC, but blue-shifted due to the shorter conjugation system. (2) 10E-isomers of the phycocyanobilin type are unstable and isomerize back rapidly to the more stable 10Z-isomer (Braslavski et al., 1983). If the situation is similar in the violin chromophore, the stability of the photoproducts both in the native and the denatured pigment then indicate isomerization at the 15, 16-double bond. (3) In the crystal structure of PEC (M. Dürring and R. Huber, private communication), the rings $B$ and $C$ are held rather rigidly by the propionic acid side chains, whereas ring $\mathrm{D}$ has increased rotational freedom. (d) The decreased steric hindrance between rings $A$ and $D$ in a system which is conjugated over only rings B-D, would allow more readily cyclic coplanar structures both for 15E- and 15Z-isomers (vide infra). This could also account for the lack of change in transition-dipole moment directions in the two forms of phycochrome $b$, which contrasts from such a change by $90 \pm 58^{\circ}$ in phytochrome (Björn $e t$ al., 1984). It should be noted, however, that steric hindrance in the E-isomers of biliverdins is believed to be responsible for their blue shift (Falk and Höllbacher, 1978). The observation of a similar shift in the sterically less hindered violin chromophore of PEC would then be unexpected. Clearly, more work is necessary to clarify this question.

A very distinct difference of the violin chromophore as compared to phycocyanobilin chromophores, is the reversible photoreactivity of PEC throughout, i.e. in the native, the partially denatured and the fully denatured state. The $\mathrm{Z}$ - chromophores of $\mathrm{PC}$ are unreactive in the native as well as in the fully denatured state. They isomerize only in an intermediate range of protein nativity, and even there give only small signals (John et al., 1985; but see Schmidt et al., 1988). The photostability of free 15Z-biliverdins has been analysed in detail (Falk and Thirring, 1980; Falk et al., 1979) and the inactivity there related to lack of distortions of the molecule in the Z-configured state. This leads to a relaxation of the excited state exclusively to the ground state of the Z-isomer, a mechanism which may contribute to the low fluorescence yield. In native $\mathbf{P C}$, the photochemistry is inhibited probably by rigid fixation of the chromophores, as witnessed by the high fluorescence yield (Scheer, 1982). Only in the region where this fixation is loosened, but the influence of the protein not yet fully removed, is a photochemical Z-to-E isomerization possible (John et al., 1985). This situation probably corresponds to the one in which the structurally very similar chromophore of phytochrome is present in the native chromoprotein.

The photochemistry of the PEC chromophore at any state then requires that both restrictions are removed. Ring $A$ is no longer part of the $\pi$-system. In the denatured state steric interactions between substituents at rings $A$ and $D$ are then less pronounced, because ring A no longer tends to become coplanar with the other three rings. In the native pigment, the chromophore is expected to be more mobile. Indications to this are found in the recent $\mathrm{x}$-ray crystal structure analysis of PEC (M. Dürring and $R$. Huber, unpublished),

In particular the latter interactions seem to influence photochemistry in a very subtle way. The chromophores $\alpha-84$ and $\beta-84$ are very close to the interacting surfaces of the $\alpha$ - and $\beta$-subunits located on different monomers in trimers of PC (Schirmer et al., 1987), PEC (M. Dürring and R. Huber, unpublished), and probably also of APC (MacColl et al., 1981). In PC and APC, a small but distinct reversible photochemistry is induced already by dissociation of trimers into monomers (Murakami and Fujita, 1983). Even though PEC is photochemically active throughout, the trend is the same: The amplitude of the photoinduced signal is maximum in $4 M$ urea or $1 M \mathrm{KSCN}$ where biliproteins are dissociated into monomers (MacColl and Guard-Friar, 1987). It decreases upon aggregation to trimers or even more so - to larger aggregates including phycobilisomes, and it decreases also upon unfolding of the polypeptide with higher urea concentrations. Phycoerythrocyanin is known to dissociate more readily than the other cyanobacterial biliproteins (Bryant, 1982; MacColl and Guard-Friar, 1987), and this may then be an additional reason for the large phycochrome $b$-related amplitudes found in vivo (Björn, 1979).

The reason for the decreased photochemistry in large aggregates can be twofold: It can be due to a 
reduced photoreactivity, e.g. by a decreased mobility of the chromophore which inhibits the rotation of ring $\mathrm{D}$ necessary for isomerization. It can also be due to a competition of energy transfer to lower energy phycocyanobilin chromophores with photochemistry. Kinetic studies will be necessary to distinguish them.

Possibly the most important finding of this study is the fact, that not only the aggregation state modifies the photoactivity, but that the aggregation state of PEC is vice versa reversibly influenced in response to pre-irradiation with different light qualities. To our knowledge, this effect has not yet been observed in any phycobiliprotein. Since we do not know at present the spectra of pure $15 \mathrm{E}$ - and $15 \mathrm{Z}$ $\alpha-84$ chromophores in PEC, we are unable to calculate the relative amounts of both forms in the samples after different light treatments. The finding of a reversible aggregation change and sharp bands in the ultracentrifuge, indicate nonetheless a rather large influence. This could at least principally be a molecular basis for a possible function in photomorphogenesis. A direct effect of the phycobiliproteins may be questioned on the basis of the small size of the PEC molecule primarily(?) optimized for lightharvesting. A reversible dissociation as response to different light qualities would principally offer alternative routes for signal transfer.

One such route could be based on photodynamic effects of free biliproteins. Their amounts are generally minor in cyanobacterial cells, as witnessed by the low 'leakage' fluorescence. Since free biliproteins are strongly fluorescent with lifetimes in the range of several nanoseconds (Holzwarth, 1987; MacColl and Guard-Friar, 1987; Scheer, 1987; Schneider $e t$ al., 1988), they pose a potential danger for photodynamic damage. Triplets of phycobiliprotein chromophores have to our knowledge not yet been observed directly, but there are indirect implications for their presence. Photobleaching of PC with $360 \mathrm{~nm}$ light absorbed by the chromophores, is increased in the absence of oxygen (Scheer, 1986). Photodynamic effects, which are generally believed to involve a triplet rather than a singlet state as inductor for singlet oxygen, have recently been reported for PC (Morcos et al., 1987). Photodynamic effects of free phycobilins may then represent a general or - via certain targets - more specific signal for the cell. A second possible mechanism would be related to the linker peptides. All phycobiliprotein tri- and hexamers in the phycobilisome seem to be associated with specific linkers, although they have only been characterized in a few species in detail (Bryant, 1988; Glazer, 1985; Rümbeli and Zuber, 1988). Phycoerythrocyanin from $M$. laminosus can be isolated together with two linkers of 8.9 and $34.5 \mathrm{kDa}$ (Rümbeli and Zuber, 1988). During dissociation of PEC, these linkers would be released, which could represent an even more specific signal.
Acknowledgements-This work was supported by the Deutsche Forschungsgemeinschaft, 53 Bonn, W. Germany (SFB 143, project A1). Mass culture of cells by G. Reng (Gesellschaft für biotechnologische Forschung, 3301 Stöckheim, W. Germany) is acknowledged. A phycobilisome sample was kindly provided by W. Sidler, Zürich, Switzerland. We thank R. Huber and M. Dürring (Martinsried) for helpful discussions and communication of $\mathbf{x}-$ ray results prior to publication.

\section{REFERENCES}

Bishop, J. E., H. Rapoport, A. V. Klotz, C. F. Chan, A. N. Glazer, P. Füglistaller and H. Zuber (1987) Chromopeptides from phycoerythrocyanin. Structure and linkage of the three bilin groups. J. Am. Chem. Soc. 109, 875-881.

Björn, G. S. (1979) Action spectra for in vivo and in vitro conversions of phycochrome $b$, a reversibly photochromic pigment in a blue-green algae, and its separation from other pigments. Physiol. Plant. 46, 281-286.

Björn, G. S. (1980) Phycochromes b and d: their occurence in some phycoerythrocyanin-containing blue-green algae (cyanobacteria). Physiol. Plant. 48, 483-485.

Björn, G. S., N. Ekelund and L. O. Björn (1984) Lightinduced linear dichroism in photoreversibly photochromic sensor pigments. -IV. Lack of chromophore rotation in phycochrome $b$ immobilized in vitro. Physiol. Plant. 60, 253-256.

Björn, L. O. (1979) Photoreversibly photochromic pigments in organisms: properties and role in physiological light perception. Quart. Rev. Biophys. 12, 1-25

Björn, G. S. and L. O. Björn (1976) Photochromic pigments from blue-green algae: phycochromes $\mathrm{a}, \mathrm{b}$ and $\mathrm{c}$. Physiol. Plant. 36, 297-300.

Björn, L. O. and G. S. Björn (1980) Photochromic pigments and photoregulation in blue-green algae. Photochem. Photobiol. 32, 849-852.

Bogorad, L. (1975) Phycobiliproteins and complementary chromatic adaptation. Ann. Rev. Plant. Physiol. 26, 369.

Braslavsky, S. E., A. R. Holzwarth and K. Schaffner (1983) Solution conformations, photophysics and photochemistry of bilipigments. Bilirubin- und biliverdindimethylesters and related linear tetrapyroles. Angew. Chem. 94, 670-689, Angew. Chem. Int. Ed. Engl. 22, 656-674.

Braune, W., T. Wilczok and R. Waclawek (1988) Indications for photoreversible reactions in the range of phycochrome $b$ absorption obtained by automáted microscopic image analysis of germinating Anabaena akinetes. Cytobios 54, 39-48.

Bryant, D. A. (1982) Phycoerythrocyanin and phycoerythrin - properties and occurrence in cyanobacteria. J. Gen. Microbiol. 128, 835-844.

Bryant, D. A. (1988) Phycobilisomes of Synechococcus sp. PCC 7002, Pseudanabena sp. PCC 7409, and Cyanophora paradoxa: an analysis of molecular genetics. In Photosynthetic Light Harvesting Systems. Organization and Function (Edited by $\mathrm{H}$. Scheer and S. Schneider), pp. 217-232. W. DeGruyter, Berlin.

Castenholz, R. W. (1970) Laboratory culture of thermophilic cyanophytes. Schweizer Z. Hydrol. 35, 538-551.

DeKok, J., S. Braslavsky and C. J. P. Spruit (1981) Solvent induced photoreversible reactions of $\bar{C}$-phycocyanin from Synechoccoccus sp. Photochem. Photobiol. 34, 705-710.

Dürring, $\mathbf{M}$. and $\mathbf{R}$. Huber, private communication, 1988.

Falk, H., K. Grubmayr and F. Neufingerl (1979) Zur anaeroben Photochemie von Gallenpigmenten: Die Reaktionsdichotomie der Photoisomerisierung an 
exocyclischen Doppelbindungen. Monatsh. Chem. 110 , 1127-1146.

Falk, H. and G. Höllbacher (1978) Über die Beziehung zwischen Lichtabsorption und Struktur von Bilatrienenabc. Monatsh. Chem. 109, 1429-1449.

Falk, H. and K. Thirring (1980) Zur anaeroben Photochemie von 21,24-Dimethyl-etiobiliverdin-IX gamma Z. Naturforsch. 35b, 376-380.

Furuya, M. (1983) Molecular properties of phytochrome. Phil. Trans. R. Soc. Lond. B 303, 361-375.

Füglistaller, P., H. Widmer, W. Sidler, G. Frank and H. Zuber (1981) Isolation and characterisation of phycoerythrocyanin and chromatic adaption of the thermophilic cyanobacterium Mastigocladus laminosus. Arch. Microbiol. 129, 268-274.

Gantt, E. (1986) Phycobilisomes. In Encylopedia of Plant Physiology. Vol. 19, Photosynthesis III (Edited by L. A. Staehelin and C. J. Arntzen), pp. 260-268. Springer, Berlin.

Glazer, A. N. (1985) Light harvesting by phycobilisomes. Annu. Rev. Biophys. 14, 47-77.

Glazer, A. N. (1983) Comparative biochemistry of photosynthetic light-harvesting systems. Ann. Rev. Biochem. 52, 125-157.

Holzwarth, A. (1987) Picosecond fluorescence spectroscopy and energy transfer in photosynthetic antenna pigments. In Topics in Photosynthesis: The Light Reactions (Edited by J. Barber), pp. 95-157. Elsevier, London.

John, W., R. Fischer, S. Siebzehnrübl and H. Scheer (1985) C-Phycocyanin from Mastigocladus laminosus. Isolation and properties of subunits and small aggregates. In Antenna and Reaction Centers of Photosynthetic Bacteria - Structure, Interactions and Dynamics (Edited by M. E. Michel-Beyerle), pp. 17-25. Springer, Berlin.

Köst-Reyes, E., S. Schneider, W. John, R. Fischer, H Scheer and H.-P. Köst (1987) Fast preparative isoelectric-focusing of phycocyanin subunits in layers of granulated gels. Electrophoresis 8, 335-336.

Kufer, W. (1988) Concerning the relationship of light harvesting biliproteins to phycochromes in cyanobacteria. In Photosynthetic Light Harvesting Systems. Organization and Function (Edited by H. Scheer and S. Schneider), pp. 89-93. W. DeGruyter, Berlin.

Kufer, W. and G. S. Björn (1989) Photochromism of the cyanobacterial light-harvesting biliprotein phycoerythrocyanin. Physiol. Plant. In press.

MacColl, R., K. Csatorday and D. S. Berns (1981) The relationship of the quarternary structure of allophycocyanin to its spectrum. Arch. Biochem. Biophys. 208, $42-48$.

MacColl, R. and D. Guard-Friar (1987) Phycobiliproteins. CRC Press, Boca Raton.

Martin, R. G. and B. N. Ames (1961) A method for determining the sedimentation behavior of enzymes: Application to protein mixtures. J. Biol. Chem. 236, 1372-1379.

Morcos, N. C., M. Berns and W. L. Henry (1988) Phycocyanin: laser activation, cytotoxic effects, and uptake in human arteriosclerotic plaque. Lasers Surg. Med. 8, 10-17.

Murakami, A. and Y. Fujita (1983) Occurence of photoreversible absorption changes in dissociated allophycocyanin and phycocyanin. Photochem. Photobiol. 38, 605-608.

Nies, M. and W. Wehrmeyer (1980) Isolation and biliprotein characterization of phycobilisomes from the thermophilic cyanobacterium Mastigocladus laminosus Cohn. Planta 150, 330-337.

Ohad, I., H.-J. A. W. Schneider, S. Gendel and L. Bogorad (1980) Light-induced changes in allophycocyanin. Plant Physiol. 65, 6-12.
Ohki, K. and Y. Fujita (1979a) Photoreversible absorption changes of guanidine-HCl-treated phycocyanin and allophycocyanin isolated from the blue-green alga Tolypothrix tenuis. Plant Cell Physiol. 20, 483-490.

Ohki, K. and Y. Fujita (1979b) In vivo transformations of phycobiliproteins during photobleaching of Tolypothrix tenuis to forms active in photoreversible absorption changes. Plant Cell Physiol. 20, 1341-1348.

Pratt, L. H. (1982) Phytochrome - the protein moiety. Ann. Rev. Plant. Physiol. 33, 557-582.

Rüdiger, W. and H. Scheer (1983) Chromophores in photomorphogenesis. In Encyclopedia of Plant Physiology, Vol. 16A, Photomorphogenesis (Edited by W. J. Shropshire and H. Mohr), pp. 119-151. Springer, Berlin.

Rüdiger, W., F. Thümmler and E. Cmiel (1983) Chromophore structure of the physiologically active form $\left(\mathrm{P}_{\mathrm{fr}}\right)$ of phytochrome. Proc. Natl. Acad. Sci. USA 80, 6244-6248.

Rümbeli, R. and H. Zuber (1988) Isolation and characterization of the components of the phycobilisome from Mastigocladus laminosus and cross-linking experiments. In Photosynthetic Light-Harvesting Systems: Organisation and Function (Edited by $\mathrm{H}$. Scheer and S. Schneider), pp. 61-70. W. DeGruyter, Berlin.

Scheer, H. (1982) Light reaction path of photosynthesis. In Phycobiliproteins: Molecular Aspects of Photosynthetic Antenna Systems (Edited by F. K. Fong), pp. 7-45. Springer, Berlin.

Scheer, H. (1986) Excitation transfer in phycobiliproteins. In Encyclopedia of Plant Physiology, Vol. 19. Photosynthesis III (Edited by L. A: Staehelin and C. J. Arntzen), pp. 327-337. Springer, Berlin.

Scheer, H. (1987) Photochemistry and photophysics of Cphycocyanin. In Progress in Photosynthesis Research (Edited by J. Biggins), pp. 143-149. Martinus Nijhoff, Amsterdam

Schirmer, T., W. Bode and R. Huber (1987) Refined three-dimensional structures of two cyanobacterial Cphycocyanins at 2.1 and $2.5 \AA$ resolution $-A$ common principle of phycobilin-protein interaction. J. Mol. Biol. 196, 677-695.

Schmidt, G., S. Siebzehnrübl, R. Fischer and H. Scheer (1988) Photochromic properties of C-phycocyanin. In Photosynthetic Light Harvesting Systems. Organization and Function (Edited by H. Scheer and S. Schneider), pp. 77-89. W. deGruyter, Berlin.

Schneider, S., P. Geiselhart, F. Baumann, S. Siebzehnrübl, R. Fischer and H. Scheer (1988) Energy transfer in 'native' and chemically modified C-phycocyanin trimers and the constituent subunits. In Photosynthetic Light Harvesting Systems. Organization and Function (Edited by H. Scheer and S. Schneider), pp. 469-482. W. DeGruyter, Berlin.

Song, P. S. (1983) The molecular basis of Phytochrome (Pfr) and its interactions with model receptors. In The Biology of Photoreception (Edited by D. J. Cosens and D. Vince-Prue), pp, 181-206. Society for Experimental Biology, London.

Tandeau de Marsac, N. (1983) Phycobilisomes and complementary chromatic adaptation in cyanobacteria. Bull. Inst. Pasteur 81, 201-254.

Wehrmeyer, W. (1983) Phycobiliproteins and phycobiliprotein organization in the photosynthetic apparatus of cyanobacteria, red algae, and cryptophytes. In Proteins and Nucleic Acids in Plant Systematics (Edited by U. Jensen and D. E. Fairbrother), pp. 144-167. Springer, Berlin.

Zuber, H. (1986) Primary structure and function of the light harvesting polypeptides from cyanobacteria, red algae, and purple photosynthetic bacteria. In Encyclopedia of Plant Physiology, Vol. 19, Photosynthesis III (Edited by L. A. Staehelin and C. J. Arntzen), pp. 238-251. Springer, Berlin. 